\title{
ENSINO CENTRADO NO ESTUDANTE: EVOLUÇÃO \\ DO INICIO DO CURSO DE ENFERMAGEM PEDIÁTRICA - NIVEL GRADUAÇĀO
}

\author{
Edelia del Pilar Neira Huerta* \\ Margareth Angelo*
}

NEIRA HUERTA, E. del P. \& ANGELO, M. Ensino centrado no estudante: evolução do início do Curso de Enfermagem Pediátrica - nível graduação. Rev. Esc. Enf. USP, São Paulo, 20(1):19-25, 1986.

Este trabalho apresenta a evolução do inicio do curso Enfermagem Pediatrica 1 - nivel de graduação - da Escola de Enfermagem da USP, no qual, desde 1979, $\dot{e}$ utilizada a metodologia de ensino centrado no estudante.

\section{INTRODUÇÃO}

Profundas reflexões em relação aos motivos que determinavam a negação dos alunos em realizar algumas tarefas solicitadas pelas docentes aliada à observação de que, na prática profissional, os ex-alunos não aplicavam aquilo que lhes fora ensinado, fizeram com que o grupo de docentes da disciplina Enfermagem Pediátrica da Escola de Enfermagem da USP questionasse a metodologia de ensino que empregavam em seu curso.

Como conseqüência desses questionamentos e reflexões o grupo decidiu modificar a metodologia empregada, optando pela utilização da metodologia de ensino centrado no estudante no curso de Enfermagem Pediátrica I - nível graduação (MORAES ${ }^{1}$, MORAES \& DE PAULA ${ }^{2}$, RIBEIRO et alii ${ }^{4}$ e NEIRA HUERTA et alii ${ }^{3}$ ).

Dessa forma, os alunos dos vinte grupos que, a partir de 1979, experimentaram a nova metodologia têm apresentado atitude mais positiva em relação às situações de aprendizagem do que no método anteriormente empregado. Eles se interessam mais por Enfermagem $\mathrm{Pe}$ diátrica, mostram maior compreensão tanto da criança e de sua familia como de suas necessidades, e os relatos verbais e escritos de suas experiências no curso revelam mudanças de percepção, de conhecimentos, de habilidades e de atitudes, mudanças estas que evidenciam a ocorrência de aprendizagem efetiva.

* Enfermeira. Mestre em enfermagem. Professor Assistente do Departamento de Enfermagem Materno-Infantil e Psiquiátrica da Escola de Enfermagem da USP - disciplina Enfermagem Pediátrica. 
Não obstante, apesar desses resultados o início do curso não foi fácil para grande parte desses alunos. Muitos deles reagiram à nova metodologia com elevado grau de ansiedade.

A análise das percepções e experiências das docentes nos diferentes grupos levou-nos a identificar, como causa provável dessa ansiedade, o fato de que os estudantes, habituados desde o curso primário a ser dirigidos pelos professores em relação àquilo que devem aprender e à forma como esse aprendizado deve acontecer, ao perceberem que, no curso de Enfermagem Pediátrica, não mais serão dirigidos, mas que, pelo contrário, serão livres para decidir quanto à direção de sua aprendizagem, processo este que será facilitado pelas docentes, descobrem que não sabem o que necessitam e desejam aprender nem como aprendê-lo.

A experiência nos diferentes grupos tem demonstrado que o elevado grau de ansiedade dificulta e retarda o estabelecimento de um relacionamento de confiança aluno-professor, relacionamento este que acreditamos ser essencial à aprendizagem efetiva e duradoura.

Preocupadas com acelerar o estabelecimento desse tipo de relação, de maneira a permitir o máximo aproveitamento do aluno em uma disciplina de oito semanas de duração, e tendo identificado o início do curso como sendo decisivo para o andamento e para os resultados do mesmo, através dos grupos temos buscado e experimentado diversas formas para dar inicio ao curso.

Neste artigo nos propusemos a apresentar a evolução do inicio do curso de Enfermagem Pediátrica I nestes seis anos de experiência com a utilização da metodologia de ensino centrado no estudante.

Para : tingir esse objetivo nos basearemos em três momentos que se apresentam como constantes no início do curso; eles são:

- apresentação dos diferentes integrantes do grupo que participarão da experiência de aprendizagem de Enfermagem Pediátrica;

- orientação ao curso; e

- tomada de decisões e definição do caminho a ser percorrido pelo grupo durante o curso.

\section{INICIO DO CURSO NOS SEIS ANOS DE EXPERIENCIA NA UTILIZAÇÃO DA NOVA METODOLOGIA}

\section{9 e 1980:}

Para a apresentação dos diferentes integrantes dos grupos de 1979 (2 grupos) e de 1980 (4 grupos), dispúnhamos as carteiras em círculo, convidando, a seguir, os alunos a se apresentarem, apresentação esta que se limitava apenas à verbalização do próprio nome.

Continuando, cada docente dizia seu nome e, geralmente, a pedido dos estudantes. completávamos essa apresentação com informações rela- 
tivas ao tempo de docência, aprimoramento profissional e até algumas informações pessoais como estado civil e número de filhos.

A seguir era feita a orientação ao curso através de uma breve exposição oral do funcionamento do curso, cujo conteúdo indicava apenas o desejo de proporcionar uma situação onde os interesses e necessidades dos alunos orientariam os objetivos a serem alcançados. Posteriormente os alunos eram convidados a formular suas expectativas e necessidades de aprendizagem em Enfermagem Pediátrica, assim como as situações que, segundo eles, lhes permitiriam melhor aproveitamento.

À medida que os alunos manifestavam suas necessidade e expectativas, estas eram registradas na lousa; o mesmo era feito com as estratégias ou situações de aprendizagem por eles identificadas. A partir desse levantamento, os alunos decidiam em relação ao início da programação do curso.

Ao analisar o ocorrido nesses grupos percebemos que, apesar do interesse inicial e geral demonstrado, era reduzido o número de alunos que participam ativamente desses primeiros momentos do curso e, conseqüentemente, este era organizado a partir da contribuição de poucos alunos.

\section{1}

Nos três grupos de alunos desse ano manteve-se tanto a apresentação dos diferentes integrantes do grupo como a orientação ao curso utilizadas nos grupos anteriores.

Com a finalidade de favorecer a participação de todos os alunos nas decisões sobre o caminho a ser percorrido durante o curso, passamos a realizar entrevistas individuais com os mesmos, nas quais lhes solicitávamos que, respondessem às seguintes perguntas:

1. O que você achou da nossa proposta?

2. De que maneira você acha que pode participar da organização inicial do curso? programa?

3. Quais as suas necessidades que você espera sejam atendidas pelo

4. Em que tipos de situações de aprendizagem você se sente mais satisfeito?

5. Como você se sente no curso de Enfermagem?

As respostas dos alunos eram tabuladas e posteriormente copiadas no quadro negro para, dessa maneira, facilitar as decisões em relação ao início da programação, bem como às estratégias que seriam utilizadas.

Com a introdução das entrevistas individuais houve participação de todos os alunos, bem como maior conhecimento dos estudantes por parte das docentes. Percebemos, porém, que vários alunos mostravam-se ini- 
bidos durante as entrevistas que eram realizadas nas salas individuais das docentes.

1982

Nesse ano mantivemos, para os três grupos de alunos, a apresentação dos integrantes do grupo, mas a orientação ao curso foi baseada fundamentalmente na apresentação das características dos elementos que compõem um curso, quando empregada a metodologia de ensino centrado no estudante. Esta orientação continuou sendo realizada através de exposição oral da docente responsável pela disciplina.

A fim de facilitar o levantamento tanto das necessidades e motivações dos alunos, bem como dos meios a serem utilizados para seu atendimento, realizamos entrevistas em pequenos grupos, de 6 a 8 alunos, nas quais, para favorecer a compreensão por parte dos estudantes, utilizamos as seguintes perguntas: na?

1. O que vocês acharam da metodologia adotada por nossa discipli-

2. O que vocês gostariam de aprender durante este curso?

3. Como vocês acham que aprendem melhor?

4. Como vocês se sentem no curso de Enfermagem?

As entrevistas em pequenos grupos permitiram-nos solucionar os dois problemas antes identificados, ou seja, através das entrevistas em pequenos grupos facilitamos a participação de todos os alunos, como, também, contribuímos para criar um clima em que eles se sentiam mais à vontade, talvez por sentirem que compartilhavam com seus colegas, da responsabilidade pelas respostas.

As informações assim colhidas foram tabuladas e os resultados copiados em transparências, fazendo um paralelo com o conteúdo que daríamos se fosse utilizado o método tradicional. Esta estratégia fez com que os alunos percebessem que eram capazes de descobrir o conteúdo básico de Enfermagem Pediátrica e, mais confiantes, se dedicassem a elaborar a programação inicial do curso, bem como a definir os meios que utilizariam para cumpríla.

1983

Nos três grupos de alunos desse ano optamos por empregar a estratégia de «Apresentação Um do Outro» para a apresentação dos alunos, na qual cada estudante escolhe um colega e o apresenta aos demais integrantes do grupo. A apresentação das docentes manteve-se igual à dos grupos anteriores. A seguir, foi solicitado aos alunos que avaliassem a estratégia utilizada. Ao fazê-lo, eles manifestaram surpresa pela forma como eram percebidos pelos colegas, identificando a experiência como significativa. 
Com a intenção de reforçar a orientação ao curso, que manteve as características do ano anterior, cada aluno recebeu material escrito contendo, em forma resumida, as principais características da metodologia empregada, bem como a definição das funções no curso, tanto dos estudantes quanto das docentes. Este reforço contribuiu para uma melhor compreensão do papel de cada um dos membros do grupo no processo em que estávamos envolvidos.

O levantamento das necessidades de aprendizagem dos alunos e dos meios que permitiriam atendê-las, bem como o tratamento das informações obtidas, foram mantidos como no ano anterior.

Os alunos desse ano apresentaram maior facilidade em elaborar a programação que daria início às atividades teóricas e práticas. Ainda assim, identificamos ansiedade elevada em um número importante de alunos.

Preocupadas com esse fato, mais uma vez consultamos e estudamos as experiências pessoais de ROGERS ' na facilitação de cursos. Ele também identificára essa elevada ansiedade inicial e, para reduzí-la, estabelecia limites perceptíveis como estrutura do curso, o que permitia que os estudantes pudessem, comodamente, começar a trabalhar e a se desenvolver com inteira liberdade. Segundo ROGERS ${ }^{5}$, a liberdade parece menos geradora de ansiedade quando se apresenta em claros termos convencionais, como uma série de exigências, recomendando também, o oferecimento do maior número de recursos de aprendizagem, de fácil acesso para os alunos, a fim de diminuir sua ansiedade.

A partir desse estudo resolvemos tentar definir uma estrutura para nosso curso, conseguindo elaborar um material escrito * para facilitar a orientação ao curso e definir algumas exigências que os alunos deveriam cumprir durante a disciplina (NEIRA HUERTA et alii ${ }^{3}$ ).

\section{4 e 1985}

Dessa maneira, nos grupos de 1984 e 1985 continuamos com a «Apresentação Um do Outro», só que desta vez iniciada pela apresentação das docentes, para facilitar a compreensão de seu funcionamento e, como nos grupos do ano anterior, convidando os alunos a avaliarem a experiência quando terminadas as apresentações.

A orientação ao curso é realizada através da leitura e discussão do «Manual de Orientação ao Curso», em pequenos grupos de alunos, com a presença de uma docente que se preocupa em estimular constantemente os alunos a expressarem suas reações e percepções, bem como a formularem suas dúvidas e receios. Durante a leitura desse material a docente empenha-se, também, em mostrar sua compreensão das verbalizações de cada aluno e em esclarecer as dúvidas por eles apresentadas.

Nessa ocasião enfatisamos que a liberdade para aprender Enfermagem Pediátrica que lhes oferecemos implica também em liberdade para optar por serem dirigidos durante o curso.

\footnotetext{
- material a ser publicado no próximo númera.
} 
Já durante a leitura desse material tem sido possivel constatar o estabelecimento de confiança de alguns alunos no docente, ficando, desse modo, demonstrada á eficácia desta medida para diminuição da ansiedade.

Apesar de acreditarmos que todos os estudantes são capazes de descobrir o conteúdo mínimo de Enfermagem Pediátrica (RIBEIRO et alii ${ }^{4}$ ), percebemos que alguns, devido à elevada ansiedade, levavam muito tempo para descobrílo, fato que aumentava ainda mais sua ansiedade, especialmente quando considerada a brevidade do curso. Por outro lado sentimo-nos responsáveis por colocar à disposição da criança, de sua familia e da comunidade colegas enfermeiros que tenham um mínimo indispensável de formação em Enfermagem Pediátrica. Devido a esses motivos, a partir do terceiro grupo de 1984, anexamos ao manual de orientação, fornecido aos alunos, aquele conteúdo de Enfermagem Pediátrica que, de acordo com nossas experiências profissionais, consideramos básico.

Em relação aos diferentes recursos de aprendizagem, a partir de 1984 destinamos vários períodos, da primeira semana do curso, ao contato dos alunos com esses recursos (NEIRA HUERTA et alii ${ }^{3}$ ). Para este fim realizamos com os alunos visitas aos diferentes campos de aprendizado prático. Dedicamos, também, dois períodos completos ao contato com recursos bibliográficos (livros, periódicos, monografias e um grande número de apostilas sobre os diversos assuntos de Enfermagem Pediátrica especialmente preparadas para os alunos), contato este que é realizado tanto em sala de aula como na Biblioteca da Escola, sempre com a presença de docentes, a fim de atenderem possiveis solicitações de orientação.

Em cada um desses contatos recomendamos aos alunos para se concentarem na tarefa de se perceber nas diferentes situações, isto com a intenção de lhes facilitar o preenchimento do Contrato Pessoal de Trabalho que ocorre em reunião de pequeno grupo no último dia da primeira semana do curso (NEIRA HUERTA et alii ${ }^{3}$ ).

Após terem preenchido seus contratos pessoais de trabalho, o grupo todo se reúne para trocar, analisar e refletir sobre suas percepcōes e experiências da primeira semana de curso, decidindo, finalmente, o rumo que o curso tomará a partir desse momento.

Desde que a análise, tanto das avaliações dos estudantes como das percepções das docentes em relação ao ocorrido no início do curso, com os últimos grupos, revela diminuição da ansiedade inicial dos alunos a niveis desejáveis para o bom aproveitamento no curso, e, tendo constatado rápido estabelecimento de uma atmosfera de confiança aluno-professor, acreditamos ter encontrado e estar implementando o inicio do curso do modo mais satisfatório possivel.

Pretendemos futuramente continuar divulgando nossas percepções e nossa experiência em relação ao emprego da metodologia de ensino centrado no estudante, aplicada ao curso de Enfermagem Pediátrica - nível graduação. 
NEIRA HUERTA, E. del P. \& ANGELO, M. Student - centered teaching: evolvement of the initial phase of the basic Pediatric Nursing Course: Rev. Esc. Enf. USP, São Paulo, 20(1):19-25, 1986.

The authors present a description of the evolvement of the initial phase of the Pediatric Nursing I Course, which, since 1979, utilizes the student - centered teaching methodology at the Nursing School of the São Paulo University.

\section{REFERENCIAS BIBLIOGRAFICAS}

1. MORAES, E. O ensino de Enfermagem Pediátrica ao nivel de graduacăo, Rev. Bec. Ene. USP, Såo Paulo, 15(2):193-203, 1981.

2. MORAES, E. \& PAULA, M. do A.O. de. Como percebí a inefíciência do ensino de Enfermagem Pediátrica no aspecto referente à assistencia aag pais. Rev. Esc. Ene. USP, Săo Paulo, 14(3):243-56, 1980.

3. NEIRA HUERTA, E. del P. et alii. O curso de Enfermagem Pediátrica I na Escola de Enfermagem da USP. Rev. Esc. Enf. USP, Săo Paulo, 19:(3):247-262, 1985.

4. RIBEIRO, C.A. et alii. A disciplina Enfermagem Pediátrica: avaliação, pelos alunos, de uma nova metodología de ensino. Rev. Esc. Ent. USP, Săo Paulo, 16(2):181-92, 1982.

5. ROGERS, C.R. Liberdade para aprender. Belo Horizonte, Interlivros, 1978, p. 69-104. 